\title{
A GESTÃO DE COMPETÊNCIAS GERENCIAIS E A CONTRIBUIÇCÁO DA APRENDIZAGEM ORGANIZACIONAL
}

RESUMO

0 presente estudo analisa os principais conceitos, princípios e práticas de aprendizagem organizacional como um meio de se tratar a questão da gestão de competências gerenciais a partir da especificidade de cada organização. Trata-se de uma pesquisa exploratória, desenvolvida com base em um estudo comparativo entre seis empresas (três brasileiras e três australianas). Os resultad os sugerem a importância das práticas informais e a necessidade de se estabelecer uma estratégia articulada no que se refere à gestão de competências gerenciais. As experiências significativas relatadas pelos gestores entrevistad os focalizam práticas organizacionais e práticas que extrapolam o âmbito organizacional. Destaca-se a importância da construção de uma consciência social. Os principais elementos de aprendizagem organizacional que representam uma potencial contribuição para a gestão de competências gerenciais referem-se às questões da interação entre as pessoas (reflexões que privilegiam o coletivo), visão processual (desenvolvimento contínuo) e a ênfase na questão pragmática (práticas de trabalho).

\section{Claudia Cristina Bitencourt}

Unisinos

ABSTRACT This article analyses the main concepts, principles and practices of organizational learning as a way of managing managerial competencies based on the individual reality of each organization. It is an exploratory research that is developed, based on case studies in six companies (three Brazilian and three Australian). The results point out the importance of informal practices and the need to establish an articulated strategy, which regard to managerial competencies management. The significant experiences related by the managers interviewed point out organizational practices and practices that have occurred outside of the companies. It also highlights the constructive importance of a social conscience. Themain elements of organizational learning that represent a potential contribution for the managerial competencies management refer to the interactive matters between people (reflections that privilege the collective), process vision (continuous development) and the emphasis on the pragmatic matter (practices at work).

PALAVRAS-CHAVE Competências gerenciais, aprendizagem organizacional, estratégia e mudança organizacional.

KEY WORDS Managerial competencies, organizational learning, strategy and organizational change. 


\section{INTRODUÇÃO}

Em cenários empresariais nos quais existe alto nível de competição, considera-se essencial a participação dos profissionais, com o intuito de tornar a empresa mais ágil e competitiva. Cabe notar que tal participação não se limita apenas ao comprometimento com os objetivos organizacionais e o envolvimento com as decisões e processos de trabalho, porém implica melhor qualificação e capacitação.

N este contexto, a gestão de competências surge como uma resposta de capacitação e traz importantes reflexões sobre o significado do trabal ho, o papel dos indivíduose da educação contínua. Por outro lado, a ênfase dada a essa abordagem, em grande parte da literatura, limita-se à construção de um perfil ideal, com explicações behavioristas que parecem não responder adequadamente às necessidades das pessoas ou das organizações.

Este artigo tem como objetivo contribuir para uma nova proposta para o desenvolvimento de competências, baseada na complementaridade que as práticas e elementos de aprendizagem organizacional podem oferecer.

0 texto está estruturado da seguinte forma: inicialmente, apresenta-se a gestão de competências, tendo como base os principais conceitos e abordagens referentes ao tema; em seguida, trata-se da aprendizagem organizacional, levantando-se al gumas das implicações inerentes a essa abordagem e apresentando reflexões sobre seu significado; num terceiro momento, busca-se integrar as duas abordagens apresentadas anteriormente, destacando-se alguns elementos de aprendizagem que oferecem suporte ao desenvolvimento de competências baseado nas limitações e/ou necessidades que a gestão de competências pode apresentar; parte-se, então, para a descrição da metodologia e apresentação dos resultados da pesquisa, com o relato das experiências de seis empresas; por fim, são resgatadas as principais contribuições teóricas e apresentadas as conclusões, enfatizandose os três princípios da aprendizagem organizacional que parecem ser fundamentais para o desenvolvimento de competências: a abordagem coletiva (interação entre as pessoas), o desenvolvimento contínuo (visão processual) e a ênfase em ações (práticas de trabalho).

\section{GESTÃO DE COMPETÊNCIAS}

A literatura na área de estudos organizacionais é rica em conceitos relacionados a competências. N este artigo, a ênfase é na formação gerencial. Com isso, os conceitos relativos às competências organizacionais ou essenciais não serão destacados.

No âmbito da gestão de competências gerenciais, várias correntes de estudos se destacam: a americana, a latino-americana, a francesa e a australiana. Os principais aspectos abordados por essas correntes e alguns de seus mais notáveis autores podem ser encontrados no Quadro 1.

Pode-se afirmar que existe a necessidade de construir um conceito mais relacional acerca da gestão de compe-

Quadro 1 - Aspectos abordados pelas diferentes correntes de pensamento sobre gestão de competências.

ASPECTOS ABORDADOS

Formação

Capacitação (aptidão)

Ação (em oposição a potencial)

Articulação de recursos (mobilização)

Resultados

Perspectiva dinâmica (questionamento constante)

Autodesenvolvimento

Interação

\section{PRINCIPAIS AUTORES}

Boyatizis (1982), Parry (1996), Boog (1995), Becker (2001), Spencer e Spencer (1993), Magalhães et al. (1997), Hipólito (2000), Dutra et al. (1998),Sandberg (1996)

Moscovici (1994), Magalhães et al. (1997), Dutra et al. (1998), Zarifian (2001)

Sparrow e Bognanno (1994), Durand (1998), Cravino (1997), Ruas (1999), Moscovici (1994), Boterf (1997), Perrenoud (1998), Fleury e Fleury (2000), Davis (2000), Zarifian (2001)

Boterf (1997)

Boyatizis (1982), Sparrow e Bognanno (1994), Parry (1996), Hase et al. (1998), Becker et al. (2001), Spencer e Spencer (1993), Cravino (2000), Ruas (1999), Fleury e Fleury (2000), Hipólito (2000), Dutra et al. (1998), Davis (2000), Zarifian (2001)

Hipólito (2000)

Bruce (1996)

Sandberg (1996) 
tências, privilegiando aspectos contextuais. Com base nessas premissas, devem-se destacar as abordagens de Boterf (1997), baseada na mobilização e articulação, e a de Sandberg (1996), baseada na interação.

As contribuições desses autores não estão focadas somente na definição dos atributos de competências (conceitos), como a maior parte das abordagens desenvolvidas sobre o tema, mas na sua aplicação (práticas). 0 trabal ho de Sandberg critica o conceito tradicional de competências: um conjunto de conhecimentos, habilidades e atitudes; ou seja, a aquisição de atributos (abordagem racionalista). Conforme argumenta 0 autor: "Por meio da análise de competências, eu estou cada vez mais convencido que os aspectos essenciais da competência humana não podem ser reduzidos a uma lista externa de atributos relacionados ao trabalho" (Sandberg, 1996, p. 20). Para ele, o desenvolvimento de competências deve ser compreendido com base nas práticas organizacionais, focalizando sua análise no enriquecimento de experiências e vivências (abordagem interpretativa). "M ais especificamente, nós destacamos que o desenvolvimento de competências envolve a mudança na estrutura e no significado das práticas de trabalho" (Sandberg e Dall'Alba, 1996, p. 411). A questão, então, refere-se não apenas ao que constitui as competências, mas também a como as competências são desenvolvidas. Em suma, Sandberg (2000) propõe a compreensão do significado do trabaIho como a primeira fase para a definição de competências. Para o autor, o desenvolvimento desse conjunto de conhecimentos e habilidades envolve a mudança na compreensão do trabalho. Para a definição da visão de competência parte-se da compreensão ou da forma como os gestores enxergam as competências.

Com isso, deve-se tratar a questão como "visão compartilhada de competências". N esse contexto, as competências se desenvolvem por meio da interação entre as pessoas no ambiente de trabalho, privilegiando a questão da complementaridade; ou seja, não se limitam ao desenvolvimento de um perfil idealizado de gestor ("super-homem") nem a listas infindáveis de atributos, mas se traduzem em práticas gerenciais complementares ou em ações gerenciais articuladas (consolidação de competências coletivas). 0 ciclo de competência é apresentado por Sandberg (2000) como uma maneira de unificar a compreensão e a aplicação das competências, quebrando a visão reducionista e racionalista do modelo tradicional.

Boterf (1997), por sua vez, vale-se de três eixos principais, que consideram a formação pessoal (biografia, socialização), a formação educacional e a experiência profissional. Ressalta, ainda, os aspectos referentes à responsabilidade e legitimidade na construção da noção de competência. A responsabilidade implica o domínio do métier e o engajamento responsável na atividade, enquanto a legitimidade se associa ao reconhecimento por parte dos superiores, pares, subordinados, em relação à capacidade de agir e de responder às situações (Ruas, 2000).

As propostas de Sandberg (1994) e de Boterf (1997) ressaltam aspectos importantes que contribuem para a reflexão do tema e são destacados na figura 1 . Os aspectos voltados à interação entre as pessoas, ao significado da competência e à experiência vêm da abordagem de Sandberg (1994). A ênfase na articulação, na legitimação e na formação vem da abordagem de Boterf (1997). As abordagens se complementam. Assim: (i) a interação entre as pessoas propicia uma melhor articulação das diretrizes e dos níveis organizacionais; (ii) a identificação do significado da competência permite a sua legitimação; e (iii) a experiência relaciona-se diretamente à formação, no sentido de capacitação, que implica visão pessoal, educacional e profissional. Portanto, a competência pode ser explicada com base em sua concepção, suas redes de trabalho e seus recursos.

\section{APRENDIZAGEM ORGANIZACIONAL}

Apesar de ser vasta e crescente a literatura referente ao tema aprendizagem organizacional, existe muita discordância em relação ao que é e como ocorre a aprendizagem. "Os economistas tendem a ver a aprendizagem como simples mel horias quantificáveis nas atividades ou como formas abstratas e definidas vagamente como resultados positivos" (Dodgson, 1993, p. 376-377). A ênfase, para esse grupo, recai sobre a quantificação dos resultados. Já para os administradores a aprendizagem pode ser vista como a base para uma vantagem competitiva sustentável. Os psicólogos, por sua vez, tratam da aprendizagem examinando o processo; ou seja, a maneira como as organizações constroem e organizam seus conhecimentos e suas rotinas, observando suas atividades e sua cultura organizacional, e adaptando e desenvolvendo a eficiência organizacional por meio da melhoria de habilidades em relação à força de trabalho. É conveniente integrar essas perspectivas em uma abordagem interdisciplinar.

A aprendizagem organizacional refere-se a "como" a aprendizagem acontece; isto é, os processos de construção e utilização do conhecimento (perspectiva processual). Destacam-se al guns conceitos que devem ser associados ao conceito de aprendizagem organizacional: (i) 
processo (em termos de continuidade); (ii) transformação (baseada na mudança de atitude); (iii) grupo (enfatizando o coletivo); (iv) criação e reflexão ( sob a ótica da inovação e da conscientização) e; (v) ação (apropriação e disseminação do conhecimento, a partir de uma visão pragmática).

Stata (apud Wick e León, 1996, p. 128) destaca dois componentes relevantes para a aprendizagem organizacional: os insights, que são conhecimentos e modelos mentais compartilhados que todos os tomadores de decisão devem aprender juntos para que a mudança não seja bloqueada; e a memória organizacional, que depende da utilização de mecanismos institucionais para reter o conhecimento. É importante compartilhar insights, conhecimentos, crenças e metas para que o coletivo prevaleça e a organização aprenda, isto é, para que a empresa construa sua própria realidade e sua memória, que servirão de base para aprendizados futuros. Dessa forma, a aprendizagem individual é transformada em coletiva, e o conhecimento individual é incorporado às práticas organizacionais.

A aprendizagem organizacional também envolve tensão criativa e momentos de "desconstrução", com a necessidade de desaprender para aprender. Nesse sentido, a reflexão vem à tona e as práticas vigentes na organização são questionadas, o controle assume um novo significado e a ordem e a desordem ocupam o mesmo espaço na organização. 0 paradoxo passa a ser tratado como

Figura 1 - Análise de competências - comparação entre as visões de Sandberg (1994) e Boterf (1997).

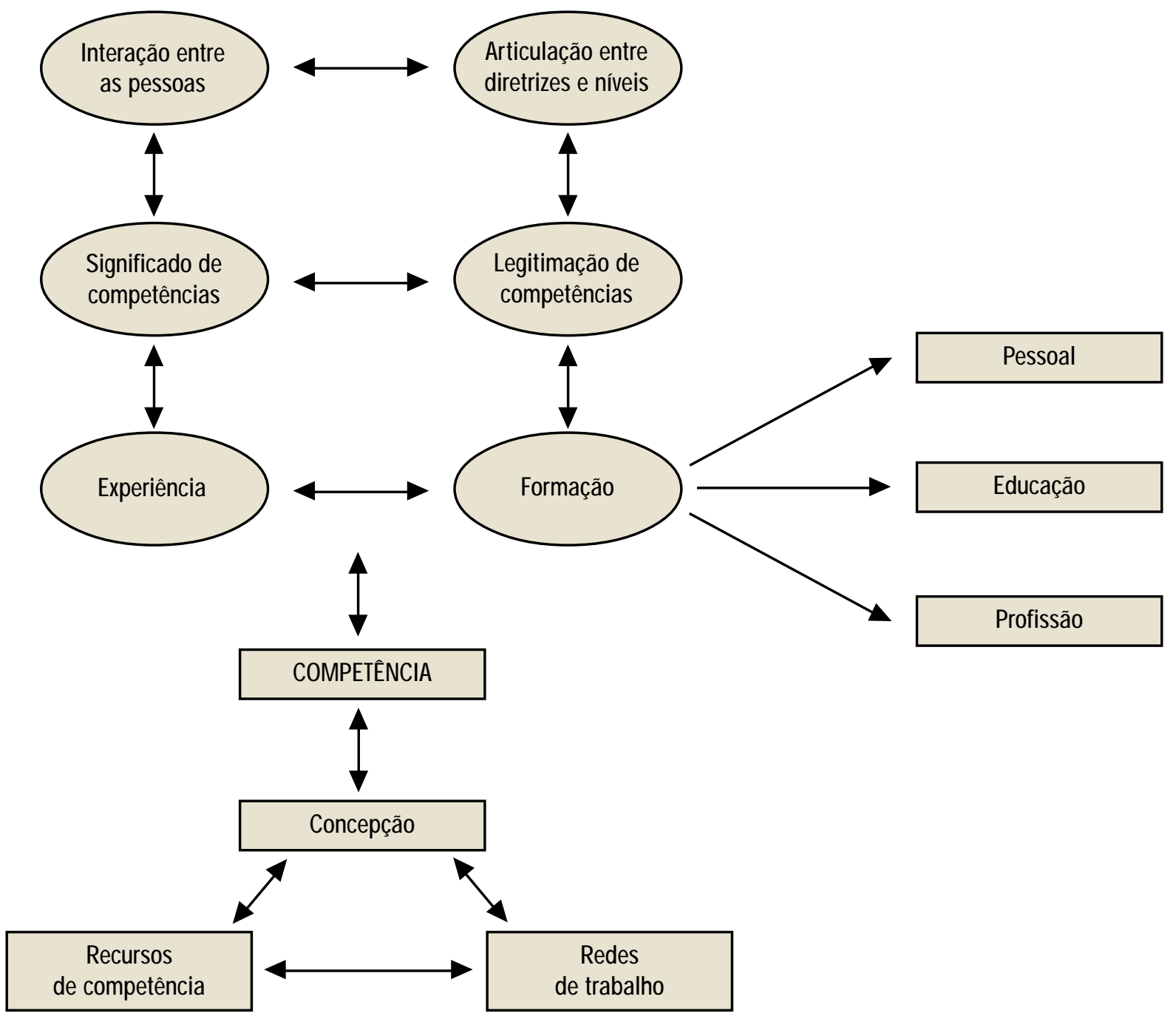


uma questão de busca do equilíbrio e não mais de pólos opostos. Segundo Fiol (1994, p. 403), "as concordâncias e discordâncias são importantes para a incorporação de esforços inovadores". Assim, alguns pontos devem ser destacados:

- Primeiro, a questão da divergência e da convergência a base para a aprendizagem organizacional é a aquisição de informações diversas e também a visão comum. A convergência e a divergência de significados são importantes para essa construção (Fiol, 1994).

- Segundo, a unificação e a diversidade - é necessário estabelecer trade-offs no processo de aprendizagem, ora privilegiando a unificação, ora a diversidade. Conforme Fiol (1994, p. 403), "a única forma de alcançar ambos é enfatizando cada um del es em um determinado momento".

- Terceiro, o compartilhamento de significado não é necessariamente uma ação organizada - o significado não é construído de maneira unidimensional, mas enfatiza múltiplas dimensões. Conforme Fiol (1994, p. 405), "o significado reside no conteúdo da comunicação, que por sua vez reflete categorias do que é expresso".

- Quarto, os modelos incrementais e radicais de aprendizagem - ambos os conceitos são relevantes para a aprendizagem, embora a teoria tenda a enfatizar o valor incremental (M iner e M ezias, 1996).

- Quinto, a questão da descrição ou prescrição - como as organizações aprendem (foco no processo)? Como as organizações deveriam aprender (foco nos resultados) ? A primeira questão enfatiza a abordagem descritiva (organizational learning), enquanto a segunda refere-se à prescritiva (learning organization). Ambas são possíveis e dependem exclusivamente dos propósitos e orientações sobre a aprendizagem organizacional (Easterby-Smith et al., 1998; Tsang, 1997).

- Sexto, criação contínua ou sistemática - a natureza da aprendizagem organizacional depende, em parte, do que se considera a "essência da organização" (EasterbySmith et al., 1998). Uma das possibilidades é en xergar a organização como um sistema, sendo focal izados os canais e fluxos de informações e o feedback. Por outro lado, ao se conceber a organização enquanto uma criação contínua, o foco transfere-se para a construção de significados, comunicação, histórias, mitos, poder formal e informal (Easterby-Smith et al., 1999).

- Sétimo, processos adaptativos e a relação entre novas possibilidades (exploration) e antigas certezas (exploitation). Ambos são essenciais para as organizações, porém, segundo March (1991), competem por recursos escassos. Como resultado, as organizações fazem escolhas implícitas e explícitas entre os dois. Segundo o autor, "aprendizagem, análise, imitação, regeneração e mudanças tecnológicas são os maiores componentes de qualquer melhoria em termos de desempenho organizacional e diferencial competitivo. Cada um deles envolve adaptação e reflete o trade-off entre exploration e exploitation" (p. 85).

As aparentes contradições ou respostas únicas são apenas uma forma restrita de enxergar a realidade. Existe uma multiplicidade de interpretações e possibilidades para se construir a abordagem em questão. Se, por um lado, isso é tranqüilizador por trazer à tona que a realidade não éúnica, por outro gera inseguranças e incertezas.

\section{APRENDIZAGEM ORGANIZACIONAL E DESENVOLVIMENTO DE COM PETÊNCIAS}

A apren dizagem organizacional podeser considerada uma resposta às mudanças enfrentadas pel as empresas em que se busca desenvolver a capacidade de aprender continuamente a partir das experiências organizacionais e a traduzir esses conhecimentos em práticas que contribuam para um melhor desempenho, tornando a empresa mais competitiva. Para tanto, a aprendizagem organizacional tem como pressuposto o desenvolvimento de estratégias e procedimentos a serem continuamente construídos para se atingirem mel hores resultados, contando com a participação efetiva das pessoas no processo de aquisição e disseminação de conhecimento. Tal condição se relaciona diretamente à questão do desenvolvimento de competências. Apesar da "cumplicidade" existente entre as abordagens apresentadas, há uma carência no que se refere à explicitação dessa rel ação. Esta seção relaciona alguns trabal hos desenvolvidos por pesquisadores da área de aprendizagem organizacional com a abordagem referente ao desenvolvimento de competências gerenciais.

A abordagem desenvolvida por Kolb (1971) foca 0 desenvolvimento do ciclo de aprendizagem baseado na vivência. Esse estudo propicia uma visão processual da apren dizagem e da formação de competências, destacando a importância da ação e da reflexão num processo contínuo que visa equilibrá-las.

Argyris (1992), por sua vez, dedica-se à discussão da lacuna observada entre a teoria assumida e aquela em uso (discurso e prática). Nesse ponto, ressalta-se a necessidade de tratar as competências como práticas observadas no ambiente de trabalho, fato esse que a diferencia do desenvolvimento de potencial. 0 autor destaca, 
ainda, a importância de refletir sobre o processo de desenvolvimento de competência a partir do erro e, assim, favorecer o desenvolvimento do double loop learning.

Senge (1990), com base no desenvolvimento de cinco disciplinas, trata a questão da competência indiretamente. Assim, o "domínio pessoal" pode ser interpretado como uma necessidade de desenvolver as pessoas tendo como base 0 autoconhecimento. Os "modelos mentais" referem-se à reflexão em ação, em que se questionam as práticas usuais observadas nas rotinas de trabal ho, procurando agregar valor às atividades da empresa a partir de uma postura mais crítica e criativa. 0 "aprendizado em equipe" retoma a importância da interação como um processo de desenvolvimento de competências coletivas e individuais, assim como o desenvolvimento da "visão comum". A última aponta para a necessidade de se promoverem construções a partir das especificidades de cada organização. 0 "raciocínio sistêmico", por sua vez, destaca a importância da visão processual em contraste à visão de eventos baseada em treinamentos formais para 0 desenvolvimento e formação de gestores.

Deve-se ainda destacar a necessidade de equilibraremse práticas individuais e coletivas, e formais e informais, para o desenvolvimento da organização e de competências gerenciais. Segundo Leonard-Barton (apud Drejer e Riis, 1999), a competência deve ser vista como um sistema. É muito difícil pensar apenas em competências individuais, uma vez que os indivíduos estão em constante processo relacional. A autora enfatiza, ainda, que os procedimentos formais e informais são fundamentais para a interação humana, e que servem de base para a construção de competências. Conforme Sitkim (2000), as organizações mais eficientes apontadas pela literatura são aquelas que integram práticas formais e informais de controle.

A literatura e as experiências vivenciadas pelas empresas demonstram que as maiores dificuldades enfrentadas referem-se a uma abordagem essencialmente individualista, prevalecendo a identificação, o desenvolvimento e a avaliação de competências individuais em detrimento de práticas coletivas voltadas à complementaridade. A carência de uma abordagem mais dinâmica limita a análise e o desenvolvimento de competências ao momento em que essas competências são mapeadas, perdendo-se a visão de "alvo móvel". Além disso, há ênfase em programas de formação e treinamento que dificilmente são incorporados às práticas de trabalho.

A aprendizagem organizacional apresenta três perspectivas que têm potencial de contribuição para a gestão de competências, enfatizando aspectos voltados ao coletivo, ao processual e ao pragmático: (i) a perspectiva so- cial refere-se à questão da formação integral em que experiências vivenciadas ao longo da trajetória pessoal e profissional representam potencial oportunidade para aprender a aprender; (ii) a perspectiva dinâmica, voltada ao desenvolvimento contínuo, ilustra a importância da visão processual e da construção de novas situações que promovam a formação e a aplicação de novas competências; e (iii) a perspectiva estratégica resgata a importância de articular as diretrizes da empresa com a visão estratégica da gestão de competências, com o intuito de sistematizar as práticas mais efetivas.

\section{METODOLOGIA E RESULTADOS}

A questão básica que norteou o estudo foi a identificação dos elementos de aprendizagem organizacional (conceitos, princípios e práticas) que podem contribuir para o desenvolvimento de competências gerenciais, agregando valor às atividades desenvolvidas nas empresas investigadas, e a manei ra como esses el ementos são desenvolvidos.

A investigação teve caráter qual itativo e exploratório, e foi realizada por meio de um estudo comparativo de seis empresas: três brasileiras e três australianas. Para definir as empresas que compuseram a amostra, foram utilizados os seguintes critérios: (i) a empresa deveria estar implementando programas voltados ao desenvolvimento de competências gerenciais; e (ii) a empresa deveria ser sensível à questão do desenvolvimento de práticas de aprendizagem organizacional. A escolha de empresas australianas justifica-se pela oportunidade de se realizar uma análise comparativa tendo como base uma realidade empresarial e cultural distinta da brasileira. Além disso, cabe observar que duas das três empresas australianas são "certificadas", o que as habilita a comercializar cursos e treinamentos para outras organizações. 0 trabal ho foi realizado em três fases.

\section{Fase I: fase exploratória inicial nas empresas brasileiras}

A primeira fase incluiu a revisão da literatura e a etapa exploratória inicial, na qual foram feitas visitas e realizadas entrevistas com pessoas da área estratégica e de recursos humanos em três organizações brasileiras do setor metal-mecânico (denominada Mecânica), de comunicação (denominada Comunica) e siderúrgico (denominada M etal). 0 objetivo foi investigar como as empresas tratavam a questão da competência. Os resultados apresentados mostram um enfoque individual (centrali- 
zação em atributos de competência desenvolvidos a partir da pessoa) enfatizado por meio das práticas organizacionais. Retornamos a essas empresas na terceira fase da pesquisa.

\section{Competências gerenciais}

As empresas brasileiras investigadas demonstram consciência da importância e necessidade de desenvolverem competências gerenciais. Entretanto, os processos observados ainda estão em fase de construção. Acredita-se na perspectiva dinâmica dessa construção, um aspecto em comum entre 0 desenvolvimento de competência e a aprendizagem organizacional.

A competência gerencial está, de al guma forma, relacionada ao negócio da empresa. O u seja, parte-se da análise das competências essenciais para se chegar às competências gerenciais. A dificuldade está na articulação do nível estratégico e operacional, e não na definição dos atributos necessários para cada um desses níveis.

A competência gerencial é tratada, ainda, com base em um perfil ideal previamente estabelecido. Existe uma tendência a construir atributos de competência ambiciosos, seja por sua abrangência, abstração e/ou diversidade (complexidade). A ênfase nessa construção é individual, o que dificulta a construção de competências coletivas.

Existe uma preocupação em diminuir ou terminar com as lacunas entre o perfil gerencial atual e o desejado. Isso é feito por meio da avaliação de competência ou desempenho. Essas avaliações encontram-se em fase inicial de aplicação, não sendo ainda possível aferir os seus resultados. Contudo, a avaliação possui um caráter quantitativo e qual itativo, e não está vinculada a nen huma forma de recompensa monetária.

\section{Aprendizagem organizacional}

As práticas de aprendizagem organizacional encontramse em fase inicial, e precisam ser amadurecidas e sistematizadas para gerarem resultados nas organizações. Os principais el ementos e práticas de aprendizagem encontrados foram os seguintes:

- Reflexão em ação - busca a melhoria de resultados e novas idéias com base em vivências no ambiente de trabalho. Baseado na tensão criativa, promove a meIhoria contínua. Exemplo: engenharia simultânea (Mecânica).

- Visão compartilhada - aproximação entre as pessoas, favorecendo a aprendizagem em grupo, com base na construção de um objetivo comum. Exemplos: estrutura matricial e gestão participativa (M etal).
- Aprender a aprender - busca aplicar novos conhecimentos e experiências em diferentes situações valendo-se do desenvolvimento da visão sistêmica e do double loop learning. Exemplo: grupos multidisciplinares (M ecânica).

- Desenvolvimento contínuo - visa aprimorar constantemente os processos, tarefas, formação e resultados da empresa. Exemplo: prática de feedback (Mecânica).

- Sistematização de processos - refere-se à incorporação de conhecimentos e práticas à organização. Dessa forma, constrói-se a memória organizacional. Exemplos: reengenharia ( $M$ etal) e engenharia simultânea (M ecânica).

Na Mecânica, a idéia original dos grupos multidisciplinares evoluiu eformaram-se grupos permanentes para trabalhar no projeto de novos produtos. A responsabilidade pela condução das reuniões aos poucos foi sendo redirecionada. Num primeiro momento, houve a tendência de o diretor ou gerente decidir os rumos da reunião e das ações a serem desenvolvidas. Aos poucos, porém, a liderança começou a ser exercida de maneira mais flexível. Assim, a decisão passou a ser compartilhada. Com o tempo, as pessoas passaram a ser preparadas para comandar os encontros, ehoje a empresa possui vários profissionais que podem exercer a liderança. Tal prática estimula o double loop learning e a visão sistêmica, enfatizando a importância da interdisciplinaridade. Resgata, também, a necessidade da reflexão em ação; ou seja, busca melhorar resultados com base em novas idéias fundamentadas nas situações vivenciadas no ambiente de trabalho e em reuniões que estimulam o diálogo e a busca conjunta de soluções.

Em 1994, a M etal sofreu um grande processo de reengenharia, passando a visualizar os processos e a ter uma visão mais sistêmica de seu trabal ho. A empresa também começou a competir com grandes indústrias internacionais e obteve mais autonomia de gestão de negócios. As pessoas passaram a trabal har em amplas salas, reunidas em uma grande mesa, e começaram a discutir os seus processos. Com base na visão processual e na sistematização dos processos organizacionais, a empresa deu um passo importante para a consolidação de sua memória organizacional, incorporando novos conhecimentos às práticas organizacionais.

Além desses exemplos, questões de estrutura e gestão, como a adoção de modelos matriciais e práticas participativas e de feedback, também foram destacadas nas entrevistas como elementos que estimularam a aprendizagem organizacional. 


\section{CLAUDIA CRISTINA BITENCOURT}

\section{Fase II: fase exploratória avançada nas empresas australianas}

A segunda fase teve como foco identificar as formas de construção de competências. N esta fase foram definidas as unidades de análise e as categorias de pesquisa, e desenvolvidos os construtos teórico e prático, relacionando os princípios da aprendizagem organizacional com 0 desenvolvimento de competências gerenciais. Em seguida foram desenvolvidos e validados os instrumentos de coleta de dados e realizada a pesquisa de campo da fase exploratória avançada, que compreendeu 13 entrevistas com profissionais ligados às áreas administrativa, de estratégia, de recursos humanos e de comunicação de três organizações australianas pertencentes aos setores de manufatura (denominada M anufact), construção (denominada Construct) e el etricidade (denominada Electric), buscando aprofundar ainda mais o construto desenvolvido nas etapas anteriores. N este momento, busca-se verificar o caráter coletivo conferido ao tratamento de competências e aprendizagem organizacional .

É importante destacar que em 1992 o governo australiano iniciou o programa conhecido como Task Force (Força Tarefa), que buscava: (i) desenvolver uma cultura positiva, por meio de educação e treinamento;(ii) estimular a educação vocacional e o treinamento, e oferecer apoio às empresas; (iii) desenvolver talentos voltados à diversidade; (iv) alcançar as melhores práticas em gestão e desenvolvimento; e (v) reformular a educação dos gestores. A fundamentação do programa era a crença de que "bons gestores são a chave para uma melhor economia competitiva e melhores resultados organizacionais" (Karpin, 1995, p. 4). A iniciativa de estimular a formação e o desenvolvimento gerencial contribuiu significativamente para a construção de um perfil gerencial que buscasse vencer as carências observadas e identificadas como lacunas: empreendedorismo, orientação global, habilidades relacionais, habilidades estratégicas e desenvolvimento gerencial.

\section{Competências gerenciais}

Em relação às três empresas investigadas, o papel do diretor executivo mostrou-se fundamental para 0 direcionamento dos processos e práticas voltados ao desenvolvimento de competências: seu perfil e suas crenças influenciam diretamente o desenvolvimento ou não dos programas de competências nas empresas.

A estrutura e o tamanho das empresas também exercem papel determinante nas práticas voltadas à gestão de competências. Assim, na empresa M anufact, uma organização enxuta em termos de estrutura e de pessoas, as práticas voltadas ao desenvolvimento de competências gerenciais são informais. Já nas outras duas empresas, Construct e Electric, não só existem programas formalizados, como as práticas voltadas ao desenvolvimento de competências encontram-se numa fase bastante madura, sendo possível identificar estratégias formalizadas.

Em relação à avaliação das competências, estas não apresentam ligação com aspectos de remuneração. A premissa é de que as pessoas devem buscar o seu desenvolvimento não por recompensas financeiras, mas pela consciência da importância e necessidade de educação permanente, voltada ao autodesenvolvimento.

Algumas práticas destacaram-se na consolidação das competências gerenciais, tais como: parceria com universidades, comunicação, trabal ho em equipe e relacionamento interpessoal. Para essas empresas, a noção de competência refere-se à formação e à ação.

\section{Aprendizagem organizacional}

Em relação aos elementos e práticas de aprendizagem organizacional, observa-se que as empresas australianas pesquisadas preocupam-se em consolidar essas experiências: as empresas Construct e Electric são até reconhecidas no país como "organizações de apren dizagem". Cabe destacar a obsessão pelo controle e pelos processos formais no ambiente das empresas australianas. Esse fato parece ser a principal diferença em termos de práticas de gestão em relação às empresas brasileiras. As empresas brasileiras caracterizam-se por estruturas informais, o que dificulta a consolidação de algumas práticas, enquanto que as empresas australianas apresentam dificuldades em estabelecer práticas mais informais, o que desfavorece uma maior aproximação entre as pessoas no ambiente de trabal ho. Os principais elementos e práticas de aprendizagem encontrados foram os seguintes, com ênfase na experiência da Electric:

- Visão compartilhada - busca de comprometimento, valendo-se da compreensão e sentido. Exemplos: trabalho em equipe ( $M$ anufact) e times de projeto (Electric).

- Raciocínio sistêmico - necessidade de desenvolver articulações entre a estratégia da empresa, processos e programas. Exemplos: questões éticas (Electric); foco em aspectos gl obais como a diversificação (Construct); e padrões de competência nacional, consolidados por meio do Programa Nacional de Competências, conhecido como Task Force (Construct e Electric).

- Tensão criativa - incentivo à reflexão em ação e busca de soluções. Exemplo: acompanhamento por mentores (Construct). 
- Melhoria contínua - política para estimular o desenvolvimento interno de estratégias, programas e processos. Exemplos: autodesenvolvimento (Manufact); TQM (Construct); plano de desenvolvimento (Electric); e revisão do progresso individual (Electric).

- Sistematização de processos - necessidade de apropriação de conhecimentos e experiências a partir da formal ização e do amadurecimento de programas, processos e práticas. Exemplos: parcerias com universidades ( Manufact, Construct e Eletrict); uso da Intranet (Construct e Electric); e participação no Programa Nacional de Desenvolvimento de Competências.

\section{Fase III: fase de aplicação de competências}

A terceira fase teve como foco identificar as formas de aplicação da noção de competência. A partir da necessidade de conhecer a percepção dos executivos acerca da gestão de competência e das práticas formais e informais de aprendizagem organizacional envolvidas nesse processo, buscou-se identificar experiências vivenciadas por esses gestores que fossem significativas para o processo de formação e desenvol vimento de suas competências e, também, atualizar os dados levantados na primeira fase junto às empresas brasileiras. Nesta fase foram realizadas três entrevistas com pessoas ligadas à área de recursos humanos e 16 entrevistas com gestores.

No que se refere às situações de aprendizagem, destacam-se as práticas que ultrapassam o âmbito organizacional, envolvendo também a vida pessoal dos profissionais. É importante salientar que as situações mais significativas levantadas pel os gestores não se referem às práticas formais e iniciativas estruturadas em relação ao programa de desenvolvimento de competências das empresas. Tal resultado é surpreendente se considerarmos 0 esforço e o investimento das empresas em seus respectivos programas de desenvolvimento de competências. Adicionalmente, pode-se especular que falta uma visão mais clara das empresas em relação ao que realmente é significativo para a formação de seus gestores.

No âmbito organizacional, no âmbito das práticas informais, parece ser relevante o papel das lideranças em estimular o desenvolvimento de competências em seus grupos de trabal ho ou mesmo sua condição de modelo a ser imitado ou seguido.

Em síntese, as experiências mais significativas apontadas pel o grupo de 16 gestores referem-se a: autodesenvolvimento, relacionamento interpessoal, desafios, satisfação social (responsabilidade social), experiência voltada a modelos de liderança, práticas do dia-a-dia, vivên- cia no exterior, papel da universidade, sistemas de gestão e projetos que estimulam a visão processual, trabalho em equipes multifuncionais, e importância da família.

Essas questões sugerem uma revisão das competências tendo como base os três eixos propostos por Boterf (1997): formação pela pessoa, formação educacional e experiência profissional, adotando-se portanto uma visão mais integrada do ser humano.

\section{CONCLUSÃO}

Esta seção retoma as principais contribuições teóricas envolvidas neste estudo, considerando-se as práticas organizacionais tratadas nas seções anteriores.

\section{Discussão}

As práticas das empresas brasilei ras pesquisadas ilustram uma tendência em iniciar a gestão de competências por um enfoque estratégico: o primeiro passo tomado pelas organizações investigadas refere-se ao mapeamento das competências organizacionais para, num segundo momento, definir as competências gerenciais. Essa situação remete à necessidade da articulação estratégica, o que confere à noção de competência um caráter dinâmico (Hipólito, 2000), voltado à ação e melhores resultados organizacionais (Boyatizis, 1982; Spencer e Spencer, 1993; Sparrow e Bognanno, 1994; Durand, 1998; Parry, 1996; Hase et al., 1998; Cravino, 1997; Ruas, 1999; M oscovicci, 1994; Boterf, 1997; Perrenoud, 1998; Fleury e Fleury, 2000; Davis, 2000; Zarifian, 1996; Becker et al., 2001).

As práticas de aprendizagem organizacional caracterizam-se pela informalidade e pela busca de soluções de problemas, tendo como base as vivências anteriores (perspectiva social). Assim, o conhecimento tácito é estimulado, principal mente pela reflexão em ação (Senge, 1990). A maior contribuição reflete-se na construção de um ambiente interativo aberto a novas aprendizagens (perspectiva dinâmica).

As empresas australianas investigadas retratam a importância conferida ao tema competências, provavelmente sob influência do investimento do governo em um programa nacional de desenvolvimento de gestores. Entretanto, essa iniciativa pode limitar as estratégias das empresas. Um perfil genérico de gestor pode dificultar a articulação entre formação gerencial e desenvolvimento articulado de estratégias e práticas organizacionais. N esse contexto, a tendência é definir um perfil ambicioso de gestor descontextual izado e, portanto, caracterizado pela 
carência de práticas articuladas que possam mobilizar os recursos necessários e específicos para cada organização (contradição das respostas únicas; Fiol, 1994).

As práticas de aprendizagem organizacional focalizam os processos formais, destacando a importância da sistematização e do controle (Easterby-Smith et al., 1998). 0 conhecimento explícito é o foco desta abordagem e traduz-se em práticas organizacionais voltadas para o uso da Intranet e na certificação da empresa como "organização de aprendizagem" (Easterby-Smith et al., 1998; Tsang, 1997).

As entrevistas com os gestores, por sua vez, mostram a importância conferida às práticas informais e às experiências vivenciadas ao longo da trajetória e da carreira profissional (Boterf, 1997; Dutra, 1998). Esta questão será retomada em seguida.
Em linhas gerais, pode-se observar a dificuldade em construir competências coletivas, o que sinaliza uma tendência a valorizar aspectos individuais, apesar da ênfase atribuída aos trabal hos em equipe. A aprendizagem organizacional parece ser uma estratégia que pode contribuir para o desenvolvimento de competências, principalmente por ser uma abordagem coletiva que: (i) dá ênfase à interação entre as pessoas; (ii) destaca o desenvolvimento contínuo; e (iii) chama a atenção para a necessidade de práticas vivenciais.

\section{Comentários finais}

Este estudo focalizou a gestão das competências gerenciais, considerando aspectos voltados ao seu desenvolvimento, acompanhamento e aval iação (ênfase no aspecto

Quadro 2 - Síntese dos resultados

\begin{tabular}{|c|c|c|c|c|c|c|}
\hline Empresas & \multicolumn{3}{|c|}{ BRASILEIRAS } & \multicolumn{3}{|c|}{ AUSTRALIANAS } \\
\hline Fatores & MECANICA & COMUNICA & METAL & MANUFAT & CONSTRUC & ELETRIC \\
\hline $\begin{array}{l}\text { Programa de } \\
\text { competências } \\
\text { formalizado }\end{array}$ & Sim & Não & Sim & Não & Sim & Sim \\
\hline $\begin{array}{l}\text { Tipologia/ atri- } \\
\text { butos de com- } \\
\text { petências }\end{array}$ & $\begin{array}{l}\text { - Conhecimentos } \\
\text { - Habilidades } \\
\text { - Atitudes }\end{array}$ & $\begin{array}{l}\text { Inicialmente: } \\
\text { - Básica } \\
\text { - Diferenciadora } \\
\text { - Estratégica }\end{array}$ & $\begin{array}{l}\text { - Técnicas } \\
\text { - Humanas } \\
\text { - Conceituais }\end{array}$ & $\begin{array}{l}\text { Base: perfil } \\
\text { genérico }\end{array}$ & $\begin{array}{l}\text { - Comunicação } \\
\text { - Habilidade em } \\
\text { negociação } \\
\text { - Solução de } \\
\text { problemas }\end{array}$ & $\begin{array}{l}\text { - Integridade } \\
\text { - Iniciativa } \\
\text { - Negociação } \\
\text { - Liderança }\end{array}$ \\
\hline $\begin{array}{l}\text { Principais } \\
\text { meios para de- } \\
\text { senvolvimento }\end{array}$ & $\begin{array}{l}\text { - Treinamento } \\
\text { operacional e } \\
\text { interpessoal } \\
\text { - Pós-graduação } \\
\text { in company } \\
\text { - Encontro de } \\
\text { gerências }\end{array}$ & $\begin{array}{l}\text { - Programa } \\
\text { de trainees } \\
\text { - Rede de } \\
\text { competências } \\
\text { compartilhadas }\end{array}$ & $\begin{array}{l}\text { - Programa de } \\
\text { trainees } \\
\text { - Universidade } \\
\text { corporativa } \\
\text { - MBAs } \\
\text { - Gestão com } \\
\text { foco no } \\
\text { operador }\end{array}$ & $\begin{array}{l}\text { - Práticas em } \\
\text { feedback e } \\
\text { autodesenvol- } \\
\text { vimento } \\
\text { - Parceria com } \\
\text { universidades }\end{array}$ & $\begin{array}{l}\text { - Programa de } \\
\text { gestão de linha } \\
\text { de frente } \\
\text { - Projeto de } \\
\text { desenvolvimen- } \\
\text { to de liderança } \\
\text { - Parceria com } \\
\text { universidades }\end{array}$ & $\begin{array}{l}\text { - Assistência } \\
\text { aos estudos } \\
\text { - Revisão do } \\
\text { progresso } \\
\text { individual } \\
\text { - Programas de } \\
\text { pós-graduação } \\
\text { - Parcerias com } \\
\text { universidades }\end{array}$ \\
\hline $\begin{array}{l}\text { Avaliação } \\
\text { sistemática }\end{array}$ & $\begin{array}{l}\text { Incentive } \\
\text { Compensation } \\
\text { System }\end{array}$ & Não & Sim & $\begin{array}{l}\text { Performance } \\
\text { Payment }\end{array}$ & Sim & Sim \\
\hline $\begin{array}{l}\text { Situações de } \\
\text { aprendizagem } \\
\text { (ênfase) }\end{array}$ & $\begin{array}{l}\text { - Grupos } \\
\text { multidisciplinares } \\
\text { - Engenharia } \\
\text { simultânea }\end{array}$ & $\begin{array}{l}\text { - Ambiente de } \\
\text { trabalho } \\
\text { diferenciado } \\
\text { - Autonomia e } \\
\text { desafios }\end{array}$ & $\begin{array}{l}\text { - Reengenharia } \\
\text { - Grupos de } \\
\text { trabalho } \\
\text { - Gestão por } \\
\text { projetos }\end{array}$ & $\begin{array}{l}\text { - Trabalho em } \\
\text { equipe } \\
\text { - Reuniões }\end{array}$ & $\begin{array}{l}\text { - Trabalho em } \\
\text { equipe } \\
\text { - TQM } \\
\text { - Intranet }\end{array}$ & $\begin{array}{l}\text { - Times de } \\
\text { projeto } \\
\text { - Intranet }\end{array}$ \\
\hline
\end{tabular}


dinâmico) e buscando identificar os el ementos de aprendizagem organizacional (conceitos, princípios e práticas).

A gestão de competências nas empresas brasileiras encontra-se em uma fase inicial de desenvolvimento, caracterizada por questionamentos relacionados à seleção e à priorização de atributos de competências. As empresas australianas, por sua vez, encontram-se num estágio mais avançado, numa etapa caracterizada pela consolidação de competências. Assim, as questões apontadas referem-se à articulação entre a gestão de competências e as estratégias organizacionais.

É relevante considerar as diferenças culturais como um elemento fundamental na definição e sustentação das estratégias voltadas ao desenvolvimento de competências. No Brasil, as práticas mais valorizadas, conforme 0 depoimento de gestores, referem-se ao contexto informal, no qual prevalecem as relações interpessoais e a maneira dinâmica de se consolidarem competências via interação. Para as empresas australianas, a ênfase é nas práticas formais, que refletem aspectos culturais voltados à priorização do controle, à formalização de parcerias entre universidades e empresas, ao desenvolvimento de programas estruturados e auditados periodicamente, e ao reconhecimento de melhores práticas. 0 quadro 2 apresenta uma síntese dos resultados para as seis empresas investigadas.

A abordagem referente à aprendizagem organizacional reforça a importância de se pensar em gestão de competências tendo como base as reflexões que privilegiem o coletivo (interações entre as pessoas), o desenvolvimento contínuo (visão processual) e a ênfase em ações (práticas de trabalho). Os resultados sugerem algumas al ternativas para reflexões aprofundadas: primeiro, acerca da lacuna entre competências individuais e coletivas, com foco na dificuldade de articular experiências e aprendizagens individuais no âmbito organizacional, com 0 intuito de promover competências coletivas; segundo, acerca da resistência em se perceberem as competências não como eventos isolados ou programas pontuais, mas como uma estratégia articulada voltada ao desenvolvimento das pessoas e da organização; terceiro, acerca da preocupação excessiva com a criação de listas de atributos, instrumentos de avaliação e metodologias complexas, privilegiando o produto (instrumento de análise) e perdendo o foco no processo (desenvolvimento articulado de competências com base nos diversos programas e estratégias organizacionais).

A partir da pesquisa realizada, sugere-se um novo conceito para as competências, que possa englobar as questões de: (i) autodesenvolvimento; (ii) práticas voltadas ao ambiente externo da empresa (convivência social); e (iii) auto-realização. Entendem-se as competências como um processo contínuo e articulado de formação e desenvolvimento de conhecimentos, habilidades e atitudes, em que o indivíduo é responsável pela construção e consolidação de suas competências (autodesenvolvimento) a partir da interação com outras pessoas no ambiente de trabal ho, familiar e/ou em outros grupos sociais (escopo ampliado), tendo em vista o aprimoramento de sua capacitação, podendo, dessa forma, adicionar valor às atividades da organização, da sociedade e a si próprio (autorealização).

\section{Artigo recebido em 19.02.2003. Aprovado em 01.10.2003.}

\section{Referências bibliográficas}

ARGYRIS, C. On organizational learning. Massachusetts: Blackwell Publishers, 1992.

BITENCOURT, C. A gestão de competências gerenciais: A contribuição da aprendizagem organizacional. 2001. Tese (Doutorado em Administração) PPGA - UFRGS, Porto Alegre, 2001.

BECKER, B.; HUSELID, M.; ULRICH, D. TheH R scorecard: Linking people, strategy and performance. Boston: Harvard Business School Press, 2001.

BO0G, G. Manual de treinamento e desenvolvimento. São Paulo: Makron Books, 1995.

BOTERF, G. Construire la competence collective de l'entreprise. Gestion, v. 22, n. 3, 1997.

BOYATIZIS, R. The competent manager: A model of effective performance. New York: Wiley, 1982.

BRUCE, C. On competence. Discussion list: http://www.ped.gu.se/biorn/ phgraph/civil/conv/compet.html 1996.

CRAVINO, L. Conceptos y herramientas de management. Administración de Desempeño, n. 24, 1997.

DALL'ALBA, G.; SANDBERG, J. Educating for competence in professional practice. Instructional Science, n. 24, p. 411-437, 1996.

DAVIS, L. The work activity briefing: A model for workplace learning and leadership. 2000. Dissertação (M estrado em Educação). Brisbane, 2000.

DODGSON, M. Organizational learning: A review of some literatures. Organization Studies, v. 21, n. 5, p. 375-394, 1993.

DREJER, A.; RIIS, J. Competence development and technology - How learning and technology can be meaningfully integrated. Technovation, v. 19, n. 10, p. 631-644, 1999. 


\section{CLAUDIA CRISTINA BITENCOURT}

DURAND, T. Forms of competence: Proceedings Fourth International Conference on Competence-Based Management. In: BRANDÃO, H.; GUIMARÃES, T. Gestão de competências e gestão de desempenho: Tecnologias distintas ou instrumentos de um mesmo construto? In: ENCONTRO ANUAL DA ASSOCIAÇÃO NACIONAL DOS PROGRAMAS DE PÓSGRADUAÇÃO EM ADMINISTRAÇÃO, 23², 1999, Foz do Iguaçu. Anais... Foz do Iguaçu: Anpad, 1999.

DUTRA, J.; SILVA, J. Gestão de pessoas por competência. In: ENCONTRO ANUAL DA ASSOCIAÇÃO NACIONAL DOS PROGRAMASDE PÓSGRADUAÇÃO EM ADMINISTRAÇÃO, 22², 1998, Foz do Iguaçu. Anais... Foz do Iguaçu: Anpad, 1998.

EASTERBY-SMITH, M.; SNELL, R.; GHERARDI, S. Organizational learning: Diverging communities of practices? Management Learning, v. 29, n. 3, p. 259-272, 1998.

EASTERBY-SMITH, M.; ARAUJO, L.; BURGOYNE, J. Organizational learning and learning organization: Developments in theory and practice. London: Sage, 1999.

EISEN HARDT, K. M. Building theories from case study research. Academy of Management Review, v. 14, n. 4, p. 532-550, 1989.

FIOL, C. Consensus, diversity and learning in organizations. Denver: University of Colorado, 1994

FLEURY, M. Gestão de competências, 1999. No prelo.

FLEURY, M.; FLEURY, A. Estratégias empresariais e for mação de competências: Um quebra-cabeça caleidoscópio da indústria brasileira. São Paulo: Atlas, 2000.

KARPIN, D. Enterprising nation: Rewarding Australia's managers to meet the challenges of the Asia-Pacific century. Executive Summary, April, 1995.

KOLB, D. Individual learning styles and learning process. MIT Sloan School, 1971. (Working paper $n^{\circ}$. 535-71).

MAGALHÃES, S.; ROCHA, M. Desenvolvimento de competências: 0 futuro agora! Revista de Treinamento e D esenvolvimento, jan., p.12-14, 1997.

$M A R C H, J$. Exploration and exploitation in organizational learning. Organizational Science, v. 2, n. 1, 1991.

MINER, A.; MEZIAS, S. U gly duckling no more: Past and future of organizational learning research. New York: University of WisconsinMadison, 1996.

MOSCOVICI, F. Equipes dão certo. Rio de Janeiro: José Olympio Editora, 1994.
PARRY, S. The quest for competencies. Training, v. 33, n. 7, p. 48$56,1996$.

PERREN OUD, P. Constrtuire des compétences, est-ce tourner le dos aux savoirs? Disponível em http://www.ordp.vsnet.ch/ResN ov98/Dos-Perrenoud.html, 1998.

ROESCH, S. O estudo de caso como estratégia de pesquisa. Seminário, Porto Alegre: PPGA/UFRGS, 1998.

RUAS, R. Competências gerenciais e aprendizagem nas organizações: U ma relação de futuro? Seminário Internacional de Competitividade Baseada no Conhecimento, São Paulo: agosto, 1999.

SANDBERG, J. Human competence at work. Göteborg: BAS, 1996.

SANDBERG, J. Understanding human competence at work: An interpretative approach. Research Seminar Series. Graduate School of Management, July, 2000.

SANDBERG, J. Understanding human competence at work: An interpretative Approach. The Academy of M anagement Journal, v. 43, n. 1, p. 9-25, 2000.

SENGE, P. A quinta disciplina. São Paulo: N ova Cultural, 1990.

SPARROW, P. R.; BO GNAN NO, M. Competency requirement forecasting: Issues for international selection and assessment. In: MABEY, C., ILES, P. (org.). M anaging Learning. London: Routledge, p. 57-69, 1994.

SITKIN, S. Sequencing control system adoption and adaptation. Research Seminar Series, Graduate School of Management, July, 2000.

SPENCER, L.; SPENCER, S. Competence at work. N ew York: John Wiley \& Sons, 1993.

TSANG, E. W. K. Organizational learning and the learning organization: A dichotomy between descriptive and prescriptive research. Human Relations, v. 50, n. 10, p. 73-89, 1997.

WICK, C.; LÉON, L. 0 desafio do aprendizado. São Paulo: Nobel, 1996.

YIN, R. Case study research: Design and methods. London: Sage, 1994.

ZARIFIAN, P. A gestão pela competência. Rio de Janeiro: Centro Internacional para a Educação, Trabalho e Transferência de Tecnologia, 1996.

\section{Claudia Cristina Bitencourt}

Professora da Unisinos. Doutora em Administração pelo PPGA-UFRGS. Interesses de pesquisa em gestão de competências, aprendizagem organizacional e mudança organizacional.

E-mail: claudiab.ez@erra.com.br

Endereço: Universidade do Vale do Rio dos Sinos - Centro de Ciências Econômicas - Av. Unisinos,

950, São Leopoldo - RS, 93022-000. 